\title{
Effects of Gasoline-Diesel Ratio on Combustion and Emission Characteristics of a Dual-Fuel CI Engine: A CFD Simulation
}

\author{
Md. Habibur Rahaman, Kazi Mostafijur Rahman*
}

Department of Mechanical Engineering, Khulna University of Engineering \& Technology (KUET), Khulna-9203, Bangladesh.

Received: July 11, 2021, Revised: August 16, 2021, Accepted: August 18, 2021, Available Online: August 22, 2021

\begin{abstract}
Recently, considerable efforts are made by the engine researches all over the world, focusing primarily on achieving ultra-low emissions of NOx (nitrogen oxides) and soot without any compromise to high thermal efficiency from dual-fuel engine. In this study, combustion performance and engine-out emission of a single cylinder gasoline-diesel dual-fuel engine are numerically investigated by employing a commercial computation fluid dynamics (CFD) software, especially developed for internal combustion engines modeling. Here, gasoline-diesel relative ratio has been varied to find its impacts on performance of a dual-fuel engine. The results show that, incylinder pressure, in-cylinder temperature and rate of heat release (ROHR) are increased with gradual increment in diesel relative to gasoline. Injecting higher amount of diesel directly inside the combustion chamber as pilot fuel might have facilitated the auto-ignition process by reducing the ignition delay and accelerated the premixed gasoline-air flame propagation. These led to shorter main combustion duration which is quite desirable to suppress the knock in dual-fuel engines. In addition, NOx emission is found to decrease with relatively higher percentage of diesel. On the other hand, with increasing gasoline ratio relative to diesel, combustion duration is prolonged significantly and led to incomplete combustion, thereby increasing unburned hydrocarbon (UHC) and carbon monoxide (CO).
\end{abstract}

Keywords: Dual-fuel Engine, Gasoline-Diesel Ratio, CFD, Rate of Heat Release (ROHR), Combustion Duration.

This work is licensed under a Creative Commons Attribution-Non Commercial 4.0 International License.

\section{Introduction}

Depletion of crude oil, unstable fuel supply/cost, growing concern on environmental pollution and imposing stringent emission regulation, have intensified the demand of clean and efficient combustion technology for internal combustion engines (ICE). In transportation sector, though diesel engines are most fuel-efficient but they suffer from excessive emissions of NOx (nitrogen oxides) and soot which require the use of expensive exhaust-gas after-treatment devices. To overcome these challenges, dual-fuel engine is gaining attention where main fuel with low reactivity is added through the intake port of the engine; a pilot fuel with high reactivity is injected in relatively small amount directly inside the combustion chamber in order to initiate the combustion of premixed or partially primary fuel-air charge [1]-[3]. Kokjohn et al. [1] investigated the effects of varying fuel reactivity on performance a gasoline-diesel dualfuel engine running with varying quantities of gasoline and diesel fuel to optimally accommodate engine load and speed changes. They achieved the dual-fuel operation by port fuel injection of gasoline and early cycle direct injection of diesel fuel. In their study it is reported that around $80 \%$ gasoline- $20 \%$ diesel has optimal fuel reactivity. Many automobile manufacturers, now a days, have been focusing on dual-fuel mode of combustion in compression ignition engine using various combination of both alternative and conventional fuels such as hydrogen, alcoholbased fuel, biogas, biodiesel, methane, natural gas, diesel and gasoline [4]-[10]. Mousavi et al. [11] investigated the effects of pilot diesel fuel injection timing and quantity in a natural gasdiesel CI engine. They found that optimizing the pilot fuel injection timing and quantity of diesel could results in an improvement in engine efficiency and reduction in the $\mathrm{CO}$ emissions though NO productions increase. Ma et al. [12] carried out an experimental study on n-heptane/diesel dual-fuel CI engine. They reported that injection timing of pilot diesel fuel has significant influences on both combustion and emission performances. NOx emissions could be reduced for premixed ratio up to 0.3 but beyond that value of premixed ratio, NOx emissions will rise up. In a study by Micklow et al. [13], it is shown that a major portion of natural gas near the cylinder wall remained unburned in a dual-fuel engine operation at part load. Use of multi-dimensional ICE modeling through the highperformance computer (HPC) facilitates the design and development of new advanced engine with high efficiency and low emission in order to meet the market demand. Computational Fluid Dynamic (CFD) is a proven tool to model the complex processes such as high-pressure fuel injection, mixture formation, ignition and flame propagation occurring inside the combustion chamber of ICE. Mattarelli et al. [14] performed CFD modeling of a 4-cylinder diesel engine, capable of operating in both diesel combustion and dual-fuel (Diesel and Natural gas) combustion modes. The modeling data demonstrated that, in dual-fuel mode of combustion, formation of soot particles, $\mathrm{CO}$ and $\mathrm{CO}_{2}$ emissions could be reduced but NOx emission remains at higher level. Lopez et al. [15] characterized the impacts of relative ratios of gasoline-diesel blends on ignition delay and flame structure in a dual-fuel engine. Increasing the gasoline ratio in the mixture lead to improved ignition delay. Similar findings have been reported by Cha et al. [16]. They found that increasing the gasoline amount decreases soot and NO emissions. Puduppakkam et al. [17] performed CFD modeling of dual-fuel engine utilizing detailed kinetics mechanisms for both the gasoline and diesel surrogate fuels with an advanced and efficient chemistry solver. Their modeling approach was able to achieve accurate representation of 
combustion phasing and better predictions of unburned hydrocarbons and $\mathrm{CO}$ emissions. They found that compared to less-reactive gasoline surrogate components such as iso-octane and toluene, most-reactive fuel component n-heptane (component in both diesel and gasoline surrogates) consumed at a much faster rate.

Studies on the performances of dual-fuel engines operating with varying gasoline-diesel ratio are very limited, especially the numerical investigation. However, this is quite pertinent to explore the different combustion strategies by varying fuel reactivity in order to extend the dual-fuel engine operating regime with optimized fuel blends. Therefore, in this study, effects of gasoline-diesel relative ratio on combustion and emission characteristics of a dual-fuel engine have been investigated. Combustion characteristics in terms of in-cylinder pressure, in-cylinder temperature and rate of heat release (ROHR) are checked whereas engine-out emissions such asoxides of nitrogen (NOx), unburned hydrocarbon (UHC) and carbon monoxide (CO) level are quantified with different blends of gasoline-diesel by employing computational fluid dynamics (CFD) modeling.

\section{Computational Approach for Modeling Dual-Fuel Engine Operation}

A commercially available software ANSYS Forte (version 18.1) incorporated with highly efficient advanced chemistry solver module CHEMKIN is used to simulate the dual-fuel engine operation. ANSYS Forte is based on the solution of full Reynolds-averaged Navier-Stokes (RANS) equations. For the compressible and gas phase flows, model transport equations of mass, momentum and energy conservation laws are formulated. RNG k- $\varepsilon$ turbulence model was used as it is extensively validated for modelling the ICE.

\subsection{Geometry and Mesh Generation}

The heavy-duty 2.44-Liter Caterpillar 3401 Single Cylinder Oil Test Engine (SCOTE) used by Kokjohn et al. [1] was modeled in this study. Engine specifications are given in Table 1. For computational domain, sector mesh technique is adopted which is quite useful to reduce the computational cost when combustion chamber of the engine is considered to be symmetrical with respect to each nozzle-hole of the injector. The engine has a six-hole injector which allows the simulation to use a $60^{\circ}$ sector $\left(360^{\circ} / 6\right)$. Therefore, a sector mesh of $60^{\circ}$ angle (Fig. 1) with periodic boundary conditions is utilized.

Table 1 Engine Specifications

\begin{tabular}{|c|c|}
\hline Engine & Caterpillar SCOTE \\
\hline No. of cylinders & 1 \\
\hline Bore & $13.72 \mathrm{~cm}$ \\
\hline Stroke & $16.51 \mathrm{~cm}$ \\
\hline Connecting Rod Length & $26.16 \mathrm{~cm}$ \\
\hline Compression Ratio & 16.1 \\
\hline Strokes Per Engine Cycle & 4 \\
\hline Engine Speed & $1500 \mathrm{rpm}$ \\
\hline No. of Nozzle-hole & 6 \\
\hline No. of Diesel Injection & Double (pulsed) \\
\hline $\begin{array}{c}\text { Total fuel mass (gasoline }+ \\
\text { diesel) [mg/cycle] }\end{array}$ & 130 \\
\hline Squish & $0.157 \mathrm{~cm}$ \\
\hline
\end{tabular}
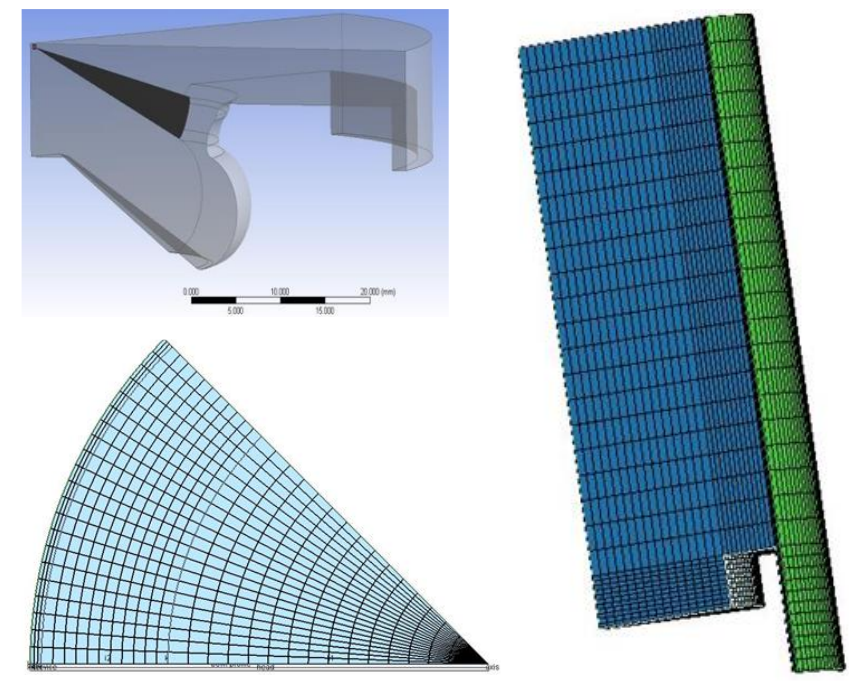

Fig. 1 A $60^{\circ}$ sector mesh for a modeling dual-fuel engine

\subsection{Ignition and Flame Propagation Models}

The thermodynamic properties and chemical reaction mechanisms of gasoline-diesel fuels available in the Lawrence Livermore National Laboratory (LLNL), USA - are added in CHEMKIN format to the chemistry model of the CFD code to simulate the dual-fuel combustion process of gasoline-diesel fuels [18]. A reduced mechanism with 425 species and 3128 reactions resulted for the reactivity-controlled compression ignition (RCCI) engine (i.e., dual-fuel) simulations [17]. In dualfuel engine, the injection and autoignition of the liquid pilot (i.e., diesel) fuel serves to initiate the flame propagation of premixed air-fuel (i.e., gasoline-air). For tracking flame propagation of premixed air-fuel, well-established G-equation model is used [19]-[20]. In ANSYS Forte, the simulation can consider both auto-ignition and flame-propagation modes of combustion progress simultaneously.

Table 2 Initial Conditions

\begin{tabular}{|c|c|}
\hline Parameters & Value \\
\hline Intake Valve Closing & $95^{\circ}$ before TDC \\
\hline Exhaust Valve Open & $130^{\circ}$ after TDC \\
\hline $\begin{array}{c}\text { Temperature at Inlet Valve } \\
\text { Closing }\end{array}$ & $350 \mathrm{~K}$ \\
\hline $\begin{array}{c}\text { Pressure at Inlet Valve } \\
\text { Closing }\end{array}$ & 4 bar \\
\hline $\begin{array}{c}\text { Turbulence Intensity } \\
\text { Turbulent Length Scale (cm) }\end{array}$ & 1.0 \\
\hline Initial Swirl Ratio & 0.7 \\
\hline Initial Swirl Profile Factor & 3.11 \\
\hline
\end{tabular}

\subsection{Initial and Boundary Conditions}

Table 2 and Table 3 present the initial and boundary conditions of the engine simulations, respectively. For all the values of gasoline/diesel ratios, these initial and boundary conditions remain the same. Turbulent law-of-the-wall velocity condition and fixed temperature walls are usually employed for 
engine simulation. Here, to capture wall boundary layer effects more accurately for boundary layers that are thinner than the mesh size, the "Law of the Wall" model is specified for piston, head and liner.

Table 3 Boundary Conditions

\begin{tabular}{|c|c|}
\hline Periodicity & 60 degrees \\
\hline Wall model & Law of the wall \\
\hline Piston Temperature & $500 \mathrm{~K}$ \\
\hline Head Temperature & $500 \mathrm{~K}$ \\
\hline Line Temperature & $430 \mathrm{~K}$ \\
\hline
\end{tabular}

\section{Results \& Discussion}

3.1 Effects of gasoline-diesel relative ratio on combustion characteristics

The influences of varying gasoline-diesel ratio on combustion performance in terms of in-cylinder pressure, incylinder temperature and rate of heat release are elucidated in Fig. 2 - Fig. 4. Increasing the relative amount pilot fuel, i.e., diesel compared to gasoline resulted in gradual increment in peak in-cylinder pressure, temperature and apparent heat release rate. With the increase of pilot diesel fuel amount, more energy is released. Consequently, apparent heat release rate (AHHR) which is the difference between chemical heat release rate and wall heat transfer loss rate, is also higher than lower diesel substitution case. From Fig. 4, it is seen that, $15 \%$ and $21 \%$ diesel cases led to higher peaks in apparent heat release rate than $8 \%$ diesel injection.

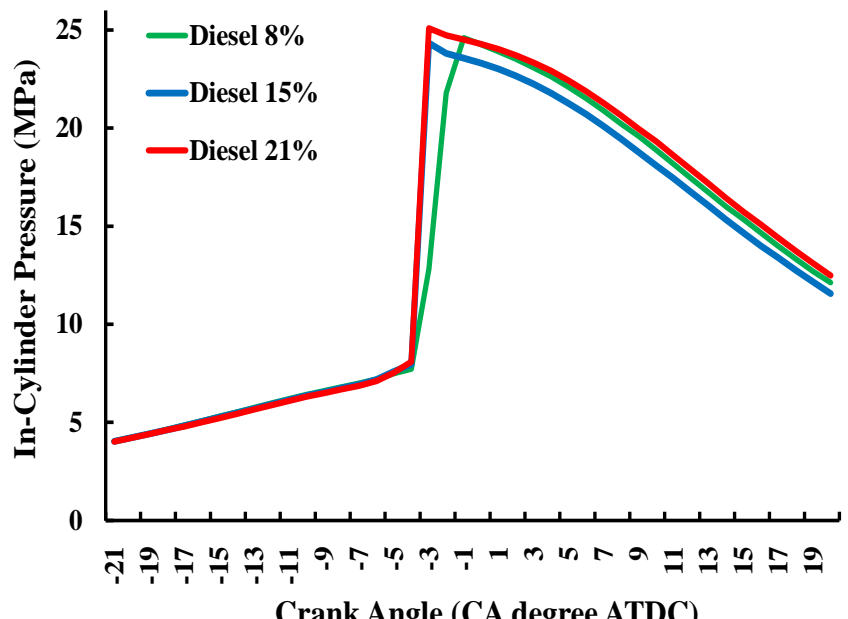

Fig. 2 In-cylinder pressure history with different gasoline-diesel relative ratio

A careful observation of Fig. 4 reveals that heat release occurred earlier for both $21 \%$ diesel and $15 \%$ diesel pilot injection cases than that for $8 \%$ diesel pilot injection. This clearly indicates that autoignition of pilot fuel as well as onset of combustion are earlier when relative amount high reactivity pilot fuel (i.e., diesel) is increased compared to low reactivity fuel (i.e., gasoline). In addition, early autoignition of pilot fuel established the fact that, ignition delay period reduced with higher percentage of pilot fuel injection.

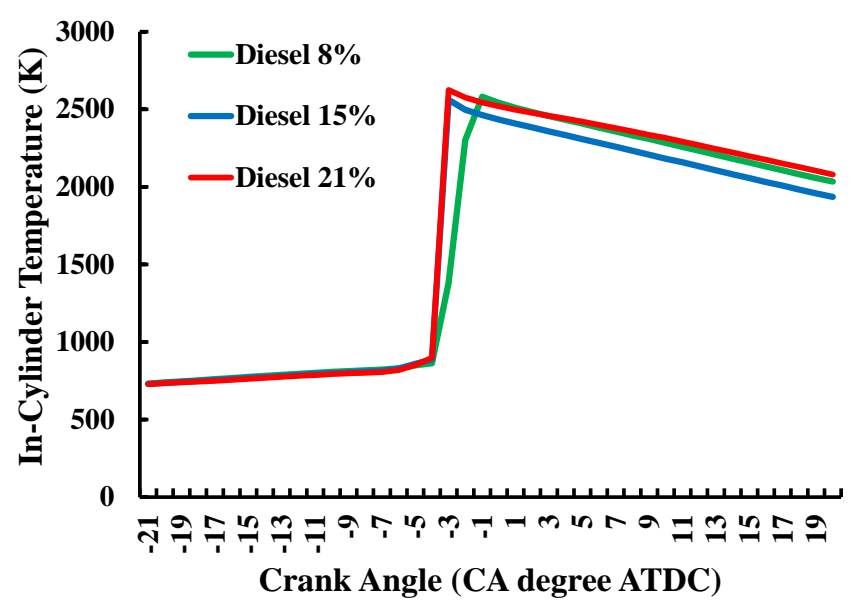

Fig. 3 In-cylinder temperature with different gasoline-diesel relative ratio

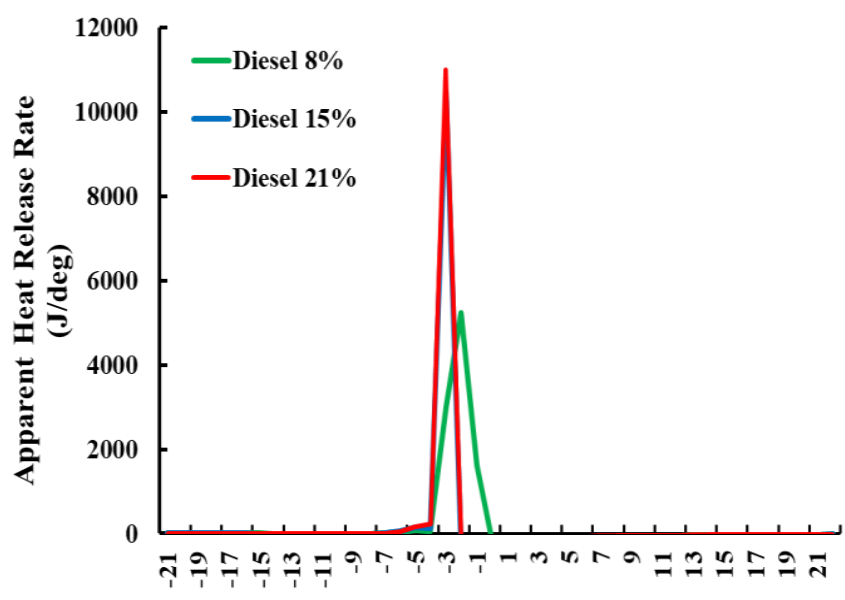

Crank Angle (CA degree ATDC)

Fig. 4 Apparent Heat Release Rate with different gasolinediesel relative ratio

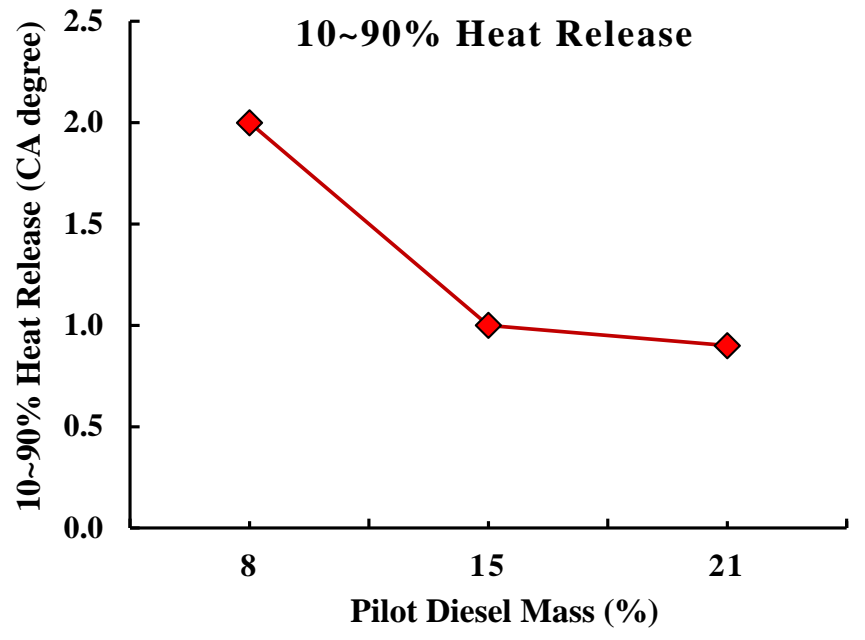

Fig. 5 Variation of main combustion duration with different gasoline-diesel relative ratio

In a dual-fuel engine, there exists pre-mixed gasoline fuel in the cylinder, therefore, the end gas may autoignite before the arrival of propagating flame front and thus SI engine type knocking may occur. Thus, shorter combustion duration is desirable in case of dual-fuel engines. 
Fig. 5 shows that, main combustion duration, which is generally defined as the duration for $10 \% \sim 90 \%$ of the heat release, is getting longer when diesel pilot fuel is injected in lesser amount, i.e., for $8 \%$ diesel-92\% gasoline case. This demonstrates that, introducing higher diesel fuel in the combustion zone accelerated the combustion reaction and subsequently led to shorter main combustion duration, which is preferable to suppress the tendency to engine knock.

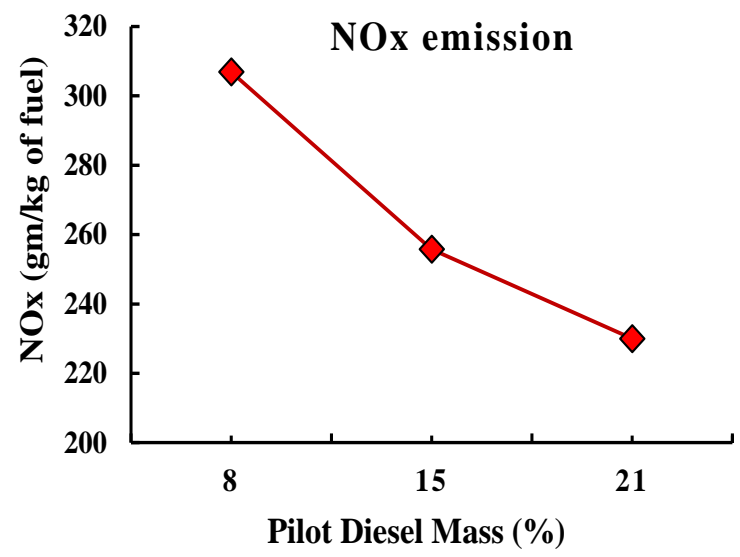

Fig. 6 Effect of gasoline-diesel relative ratio on NO formation

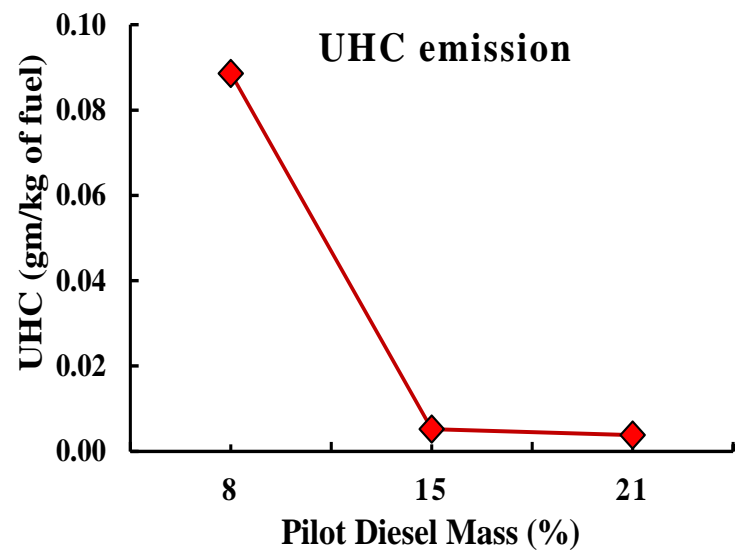

Fig. 7 Effect of gasoline-diesel relative ratio on UHC formation

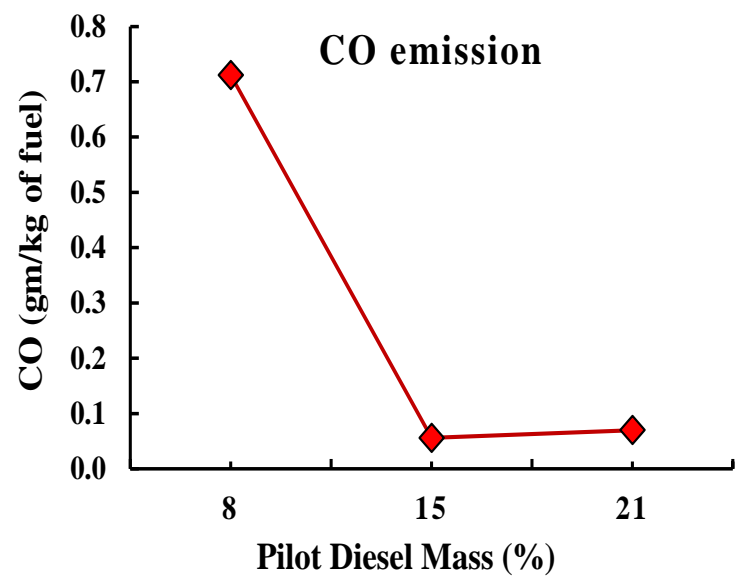

Fig. 8 Effect of gasoline-diesel relative ratio on $\mathrm{CO}$ formation

\subsection{Effects of gasoline-diesel relative ratio on engine-out} emissions

Fig. 6 to Fig. 8 represent the engine-out emissions of oxides of nitrogen, unburned hydrocarbon and carbon monoxide for different mass percentage of gasoline-diesel fuels.
It is evident from Fig. 6 that the higher percentage of gasoline led to higher level of NOx emission. Here, $92 \%$ gasoline - $8 \%$ diesel case resulted in highest NOx emission, whereas minimum NOx emission observed for $79 \%$ gasoline - $21 \%$ diesel case. Premixed flame (in this case gasoline flame) has generally much higher temperature than non-premixed/diffusion flame (i.e., diesel flame). Therefore, NOx emission is found to be higher as result of high temperature premixed flame associated with the increase of gasoline mass percentage. NOx formation is strongly influenced by two parameters namely, temperature and oxygen concentration as per Zeldovich mechanism; and it is found to increase exponentially with in-cylinder temperature [21].

8\% diesel-92\% gasoline case emits more unburned hydrocarbon (UHC) and carbon mono-oxide (CO) compared to that for $21 \%$ diesel-79\% gasoline case. This might be attributed to the fact that flame propagation is not fast enough for lower percentage of diesel to consume all pre-mixed gasoline. Moreover, flame might be quenched earlier, therefore, some gasoline remained unburned near the cylinder wall or combustion became incomplete. Hence, both UHC and CO emissions level are found to be higher with greater percentage of gasoline.

\section{Conclusions}

In this study, the influences of gasoline-diesel relative ratio on combustion characteristics in terms of in-cylinder pressure, temperature, rate of heat release, combustion duration; and engine-out emissions of NOx, UHC and CO level from a single cylinder four-stroke dual-fuel engine was investigated through computational fluid dynamics (CFD) modeling. A commercially available software incorporated with highly efficient advanced chemistry solver module CHEMKIN is used to simulate the dual-fuel engine operation. Percentage of pilot diesel is varied arbitrarily from $8 \%$ to $21 \%$ by mass. A sector mesh of $60^{\circ}$ angle with periodic boundary conditions is considered instead of using the whole engine geometry in order to reduce the computational cost and time. The major findings of this modeling are summarized as follows:

$>$ With the increase of pilot diesel fuel amount, more energy is released which resulted in higher in-cylinder pressure, incylinder temperature and rate of heat release.

$>$ Autoignition of pilot fuel as well as onset of combustion occurred earlier when relative amount high reactivity pilot fuel (i.e., diesel) is increased compared to low reactivity fuel (i.e., gasoline). Besides, ignition delay period reduced with higher percentage of pilot fuel injection.

$>$ Introducing higher amount of diesel fuel in the combustion zone accelerated the combustion reaction and subsequently led to shorter main combustion duration, which is preferable in dual-fuel engine to suppress the tendency to engine knock. Moreover, shorter main combustion duration could lead to higher thermal efficiency by reducing heat loss to cylinder wall.

$>$ Higher percentage of gasoline led to higher level of NOx, $\mathrm{UHC}$ and $\mathrm{CO}$ emissions.

\section{Acknowledgment}

We sincerely acknowledge the support of the Department of Mechanical Engineering, Khulna University of Engineering \& Technology (KUET) by providing the computing facility to conduct this CFD modelling. 


\section{References}

[1] Kokjohn, S.L., Hanson, R.M., Splitter, D.A. and Reitz, R.D., 2010. Experiments and modeling of dual-fuel HCCI and PCCI combustion using in-cylinder fuel blending. SAE International Journal of Engines, 2(2), pp.24-39.

[2] Dempsey, A.B. and Reitz, R.D., 2011. Computational optimization of reactivity controlled compression ignition in a heavy-duty engine with ultra low compression ratio. SAE International Journal of Engines, 4(2), pp.2222-2239.

[3] Benajes, J., Molina, S., García, A., Belarte, E. and Vanvolsem, M., 2014. An investigation on RCCI combustion in a heavy duty diesel engine using incylinder blending of diesel and gasoline fuels. Applied Thermal Engineering, 63(1), pp.66-76.

[4] Park, S.H., Yoon, S.H. and Lee, C.S., 2014. Bioethanol and gasoline premixing effect on combustion and emission characteristics in biodiesel dual-fuel combustion engine. Applied energy, 135, pp.286-298.

[5] Jeftić, M. and Zheng, M., 2015. A study of the effect of post injection on combustion and emissions with premixing enhanced fueling strategies. Applied Energy, 157, pp.861-870.

[6] Fraioli, V., Mancaruso, E., Migliaccio, M. and Vaglieco, B.M., 2014. Ethanol effect as premixed fuel in dual-fuel CI engines: experimental and numerical investigations. Applied energy, 119, pp.394-404.

[7] Guerry, E.S., Raihan, M.S., Srinivasan, K.K., Krishnan, S.R. and Sohail, A., 2016. Injection timing effects on partially premixed diesel-methane dual fuel low temperature combustion. Applied energy, 162, pp.99-113.

[8] Yang, B., Xi, C., Wei, X., Zeng, K. and Lai, M.C., 2015. Parametric investigation of natural gas port injection and diesel pilot injection on the combustion and emissions of a turbocharged common rail dual-fuel engine at low load. Applied Energy, 143, pp.130-137.

[9] Dimitriou, P., Tsujimura, T., Kojima, H., Aoyagi, K., Kurimoto, N. and Nishijima, Y., 2021. Experimental and Simulation Analysis of Natural Gas-Diesel Combustion in Dual-Fuel Engines. Advances in Compression Ignition Natural Gas-Diesel Dual Fuel Engines.

[10] Pham, V.C., Choi, J.H., Rho, B.S., Kim, J.S., Park, K., Park, S.K., Le, V.V. and Lee, W.J., 2021. A Numerical Study on the Combustion Process and Emission Characteristics of a Natural Gas-Diesel Dual-Fuel Marine Engine at Full Load. Energies, 14(5), p.1342.
[11] Mousavi, S.M., Saray, R.K., Poorghasemi, K. and Maghbouli, A., 2016. A numerical investigation on combustion and emission characteristics of a dual fuel engine at part load condition. Fuel, 166, pp.309-319.

[12] Ma, J., Lü, X., Ji, L. and Huang, Z., 2008. An experimental study of HCCI-DI combustion and emissions in a diesel engine with dual fuel. International Journal of Thermal Sciences, 47(9), pp.1235-1242.

[13] Micklow, G.J. and Gong, W., 2002. Mechanism of hydrocarbon reduction using multiple injection in a natural gas fuelled/micro-pilot diesel ignition engine. International Journal of Engine Research, 3(1), pp.13-21.

[14] Mattarelli, E., Rinaldini, C.A. and Golovitchev, V.I., 2014. CFD-3D analysis of a light duty Dual Fuel (Diesel/Natural Gas) combustion engine. Energy Procedia, 45, pp.929-937.

[15] López, J.J., Novella, R., García, A. and Winklinger, J.F., 2013. Investigation of the ignition and combustion processes of a dual-fuel spray under diesel-like conditions using computational fluid dynamics (CFD) modeling. Mathematical and Computer Modelling, 57(78), pp.1897-1906.

[16] Cha, J., Kwon, S. and Park, S., 2011. An experimental and modelling study of the combustion and emission characteristics for gasoline-diesel dual-fuel engines. Proceedings of the Institution of Mechanical Engineers, Part D: Journal of Automobile Engineering, 225(6), pp.801-812.

[17] Puduppakkam, K.V., Liang, L., Naik, C.V., Meeks, E., Kokjohn, S.L. and Reitz, R.D., 2011. Use of detailed kinetics and advanced chemistry-solution techniques in CFD to investigate dual-fuel engine concepts. $S A E$ International Journal of Engines, 4(1), pp.1127-1149.

[18] https://combustion.llnl.gov/archivedmechanisms/surrogates/prf-isooctane-nheptane-mixture [Accessed on 06-Mar-2020].

[19] Peters, N., Turbulent Combustion. Cambridge University Press: Cambridge, UK, 2000.

[20] Tan, Z., Reitz, R.D., 2006. An Ignition and Combustion Model for Spark Ignition Engine Multi-Dimensional Modeling. Combustion and Flame, 145, pp. 1-15.

[21] Heywood, J.B., Internal Combustion Engine Fundamentals. McGraw-Hill Publications: New York, USA, 1988. 